\title{
Prevalence of low Back Pain among Street Cleaners in Northeastern Nigeria
}

\author{
Adetoyeje Oyeyemi Yunoos', Usman Sani Dankoly ${ }^{2}$ \\ 'Department of Physiotherapy, University of Maiduguri, Maiduguri, Nigeria, ${ }^{2}$ Department of Rehabilitation Sciences and Physiotherapy, University of Antwerp, Antwerp, Belgium
}

\section{Abstract}

Context: Street cleaners assume bending and twisting positions for a long period while on the job, making them to be susceptible to low back pain (LBP). Aims: This study was aimed at determining the prevalence of LBP among street cleaners in North-eastern Nigeria. Settings and Design: Sample of convenience was to recruit 381 participants who were street cleaners working within Maiduguri Metropolitan Council. Subjects and Methods: A conveniently sampled participants $(n=381)$ completed sociodemographic form, Nordic LBP Questionnaire and LBP risk factors form. Descriptive statistics were used to summarise the data, and Chi-square statistics were used to explore the differences in LBP prevalence by sociodemographics. Results: The present study shows a 12-month LBP prevalence rate of $78.2 \%$ and a crude point ( 7 days) prevalent rate of $55.1 \%$ among the workers, and this condition tend to occur more frequently among those in the age group between 58 and 67 years than their counterparts in the lower age groups $(P=0.001)$. Male cleaners tend to report LBP more frequently than their female counterparts $(P=0.011)$, and those with primary or qur'anic education also reported LBP more frequently than their counterparts with secondary or tertiary education $(P=0.046)$. Performing the same task over and over and working in the same position for long periods were the most frequently chosen risk factors pre-disposing the workers to LBP on their job. Conclusions: The present study identified the needs for workers ergonomic education and employers' consideration for ergonomically fit tools, as potential solution to addressing LBP as an occupational hazard among the workers.

Keywords: Low back pain, North-eastern Nigeria, occupational hazards, prevalence, street cleaners

\section{INTRODUCTION}

Low back pain (LBP) is a discomfort, aching or stiffness concentrated in the lower back ${ }^{[1]}$ which occurs as a result of poor or awkward work postures, bending, lifting or in any physically strenuous job tasks..$^{[2]}$ This condition is a subset of back pain which has been described as an acute or chronic intermittent pain of long or short duration which may radiate either to the lower limbs or upper part of the body, depending on the sites of the lesion on the spine ${ }^{[3]}$ High body mass index, smoking, older age, being female, sedentary work, low educational attainment, job dissatisfaction and psychological factors such as somatisation disorder, anxiety and depression have been identified as the risk factors of LBP. ${ }^{[4]}$ LBP is a ubiquitous ailment and a common and frequent reason for seeking medical care in the many instances. ${ }^{[5]}$

Although estimates for many developing countries in sub-Sahara Africa are unavailable, previous data on developed

\begin{tabular}{|l|l|}
\hline \multicolumn{2}{|c|}{ Access this article online } \\
\hline Quick Response Code: & Website: \\
\hline & www.njbcs.net \\
\hline
\end{tabular}

countries such as the United States have shown that $28 \%$ of the populations experience disabling LBP sometime during their lives, 14\% experience episodes lasting at least 2 weeks and $8 \%$ of the entire working population will be disabled with LBP in any given year, while the lifetime prevalence of LBP has been estimated to be $69 \%-80 \%$ in the country. ${ }^{[6]}$ Previous estimates for the United Kingdom over three decades ago placed LBP as the largest single cause of absence from work in 1988-1989, and it was responsible for about $12.5 \%$ of all sick days. ${ }^{[7]}$ Over a decade ago, it was projected that the greatest

Address for correspondence: Mr. Usman Sani Dankoly, Department of Rehabilitation Sciences and Physiotherapy, University of Antwerp, Campus Drie Eiken, Universiteitsplein 1, 2610 Wilrijk, Antwerp, Belgium. E-mail: uthmansani2015@gmail.com

Submitted: 25 -Dec-2019

Revised: 25-Jul-2020

Accepted: 18-Nov-2020

Published: 04-May-2021

This is an open access journal, and articles are distributed under the terms of the Creative Commons Attribution-NonCommercial-ShareAlike 4.0 License, which allows others to remix, tweak, and build upon the work non-commercially, as long as appropriate credit is given and the new creations are licensed under the identical terms.

For reprints contact: WKHLRPMedknow_reprints@wolterskluwer.com

How to cite this article: Yunoos AO, Dankoly US. Prevalence of low back pain among street cleaners in Northeastern Nigeria. Niger J Basic Clin Sci 2021;18:24-30. 
increase in LBP prevalence in the second decade of this century will be in developing nations. ${ }^{[8]}$ Although no reliable estimate is available for Nigeria, previously in Africa and developing countries, poverty with its attendant malnutrition, infectious diseases, ignorance, and inadequate medical facilities were found to be associated with the occurrence of LBP. ${ }^{[9]}$

In many parts of Nigeria, street cleaning is still done manually, and it involves sweeping, weeding, tree pruning, and cutting and packing and carrying of refuse and dirt usually in a container. In Maiduguri street, cleaners perform their sweeping job using short brooms and their weeding and cutting job using hand tools such as hoes and cutlasses. They also use rake, as well as use head pan and wheel barrow to collect and empty the refuse collections into sanitation trucks. Street cleaners work in the morning hours cleaning the street after which toward the afternoon, collections are taken to the depots where refuse are burnt. Maiduguri is the capital city of Borno state and is the largest city in North-eastern Nigeria. This city located in the Sahel region often experiences frequent sand storms during the dry season between November and March of the year. For the most part of the year, the paved streets are often dusty, and therefore, in addition to refuse collection and disposal, street cleaners also collect and pack sand for disposal.

LBP is one of the musculoskeletal conditions that has been extensively studied in several occupational groups such as farmers, hospital workers, drivers and janitorial workers. ${ }^{[10-14]}$ A high prevalence rate of $72.4 \%$ and $67 \%$ has been reported among peasants' farmers in South-west and South-South Nigeria, respectively. ${ }^{[11,12]}$ The prevalence rate among cleaners or janitorial workers was reported as $77.2 \%{ }^{[14]}$ in South-South Nigeria and $63.1 \%{ }^{[13]}$ in South-West Nigeria. A rate of $46 \%$ among staff in the rural hospital in South-western Nigeria has been reported, ${ }^{[10]}$ while a prevalence rate of $45.5 \%$ has been reported among sanitation workers and urban cleaners in Brazil. ${ }^{[15]}$ The two Nigerian studies above were focused on cleaners employed in tertiary health institutions mostly involved in cleaning offices, wards, clinics, and surroundings, but not the streets.

Street cleaners usually assume bending and twisting positions for the long periods of time due to the requirements of their occupations making these workers to be susceptible to musculoskeletal impairments, especially LBP ${ }^{[16]}$ At present, no firm data exist on the prevalence of LBP among street cleaners and sanitation workers in the North-eastern Nigeria. Whether the workers are knowledgeable about the risks posed by some specific job tasks or duties and working condition, and the importance they attach to any of these tasks, duties, or working conditions as the factors that can pre-dispose them to LBP as job hazards is unclear. For the street cleaning workers, being able to identify the body movements, postures and job schedules and tasks durations that could pre-dispose them to developing LBP may be indications of their level of knowledge and awareness on the risk factors for LBP. This study, therefore, was aimed at determining the prevalence of LBP among street cleaners in Maiduguri and to identify what the workers perceived as important factors that could pre-dispose them to LBP.

\section{Subjects and Methods \\ Participants}

Using a sample of convenience, 381 participants who were street cleaners working within Maiduguri Metropolitan Council, and who have worked for 6 months or over were recruited for this study. The participants completed a sociodemographic form that elicited information such as age, gender, marital status, educational level and years of working experience. Participants then completed a standardized Nordic Low Back Pain Questionnaire (NLBQ) that elicited information about LBP among the workers. ${ }^{[17]}$ The test-retest reliability of the NLBQ shows the number of different answers ranged from $0 \%$ to $8 \%$, indicating that the instrument is highly reliable. Validity tested against clinical history and the NLBPQ found a range of $0 \%-20 \%$ disagreement. ${ }^{[17]}$ Comparing pain in the last 7 days shows sensitivity ranging between $66 \%$ and $92 \%$ and specificity between $71 \%$ and $81 \% \cdot{ }^{[18]}$

Participants also completed a risk factor form that elicited information about the risks to LBP to which the workers may be exposed while performing tasks on the jobs. Respondents with LBP were asked whether the 13-item risk factors contributed to the occurrence of their LBP on a Likert scale response choices consisting of 1 (irrelevant), 2 (minor or insignificant), 3 (moderate significance) and 4 (major significance). One item on the risk factor form is 'Performing the same tasks over and over' and another is 'Unanticipated sudden fall'. For this study, the questionnaire was either self-administered, or interviewer administered for those who were unable to read or write in the English language. One of the authors (UMD) administered the instrument to those who were not able to complete the questionnaire themselves using a standardised format.

\section{Procedure}

Approval of the research and ethical committee of the University of Maiduguri Teaching Hospital was sought and obtained before the commencement of this study. A cover letter stating the purpose of the study and seeking the consent of prospective participants was provided to eligible participants. Participants were assured that the information obtained will be kept strictly confidential and will be used as aggregated data purely for research purpose only. The procedure and purpose of the research were fully explained to each participant before obtaining their informed consent. Copies of the questionnaire were distributed to the participants to fill. Questionnaire was filled at the study site and collected on the same day by the researcher. Researcher returned within 1 week to collect completed questionnaires for those who choose to complete them at other times convenient for them.

\section{Data analysis}

Descriptive statistics of frequency and percentage were used to analyse the sociodemographic information (age group, gender, 
marital status and educational qualification) on the participants, effect of LBP on their physical performance and function, and the risk factors that pre-dispose the workers to LBP. The Chi-square test was used to determine the difference in the prevalence of LBP among the street cleaners by age group, gender, educational level and years of working experience, at an alpha level set as $P<0.05$.

\section{RESULTS}

\section{Sociodemographic characteristics of the participants}

A total of 400 questionnaires were given to participants within Maiduguri Metropolitan Council in Borno State and 381 were returned completed, given a response rate of $95.3 \%$. More males $(n=203,53.3 \%)$ than females $(n=178,46.7 \%)$ participated in the study. Participants were categorized into 10 year age groups beginning from the age of 18 or age of maturity and $141(37.0 \%)$ of them were in the age group between 38 and 47 years, while $52(13.6 \%)$ were in the 18-27 age group. More participants $(n=146 ; 38.3 \%)$ had primary school education, whereas only few of them had higher or tertiary education $(n=15,3.9 \%)$. Majority $(52.2 \%, n=199)$ had spent 10 or more years on the job, and only $9 \%(n=36)$ had spent 7-9 years on the job. Virtually, all of them $(96.7 \%$, $n=367)$ worked every day, and majority of them $(73 \%$; $n=278$ ) perform the cleaning duties for 4-6 h daily [Table 1].

\section{Prevalence of low back pain among cleaners}

Majority of the participants ( $n=298,78.2 \%)$ experienced LBP and $83(21.8 \%)$ reported not experiencing LBP during the last

\begin{tabular}{llc}
\hline \multicolumn{2}{l}{ Table 1: Frequency distribution of participants by } \\
Sociodemographic characteristics \\
\hline Variable & Categories & Frequency (\%) \\
\hline Age group (years) & $18-27$ & $52(13.6)$ \\
& $28-37$ & $83(21.8)$ \\
& $38-47$ & $141(37.0)$ \\
& $48-57$ & $81(21.3)$ \\
& $58-67$ & $24(6.3)$ \\
Gender & Male & $203(53.3)$ \\
& Female & $178(46.7)$ \\
Educational level & Qur'anic school & $138(36.3)$ \\
& Primary & $146(38.3)$ \\
& Secondary & $82(21.5)$ \\
& Tertiary & $15(3.9)$ \\
Years of working & $1-3$ & $86(22.6)$ \\
experience & $4-6$ & $60(15.7)$ \\
& $7-9$ & $36(9.5)$ \\
& $\geq 10$ & $199(52.2)$ \\
Work status & Daily & $367(96.7)$ \\
& Alternate days & $8(2.1)$ \\
Duration of cleaning & Occasionally & $6(1.2)$ \\
per session (h) & $1-3$ & $26(6.8)$ \\
& $4-6$ & $278(73.0)$ \\
& $7-9$ & $69(18.1)$ \\
& $\geq 10$ & $8(2.1)$ \\
\hline
\end{tabular}

12 months, while 55.1 reported back trouble in the past 7 days. A substantial number of the participants $(19.8 \%, n=64)$ have been hospitalised because of LBP and majority $(n=291$, $76.4 \%$ ) responded 'Yes' when asked whether they had to change jobs or duties because of low back trouble in the past year. Seventy-two (18.9\%) reported 'Yes' when asked whether they were experiencing low back trouble every day during the last 12 months, while 17 (4.5\%) reported experiencing low back trouble 8-30 days during the last 12 months. Low back trouble caused $82.9 \%(n=316)$ of the street cleaning workers to reduce their work activity both at home and away from home during the last 12 months while $77.7 \%(n=296)$ reduced their leisure activity during the past 12 months. This condition prevented $19.4 \%(n=74)$ of the participants from doing their normal work (at home and away from home) for 1-7 days during the last 12 months. About 40\% $(n=102)$ reported 'Yes' when asked whether they have been seen by a doctor, physiotherapist or other health practitioners because of low back trouble during the past 12 months [Table 2].

\section{Differences in the prevalence by sociodemographic characteristics}

The prevalence of LBP was significantly higher $(P<0.0002)$ among those in the 58-67 years and 48-57 years age groups (91.7\% and $90.1 \%$, respectively) than the lower age groups, and the prevalence rate was least among the 18-27 years age group with the prevalence rate of 59.6\% [Table 3]. Cleaners in older age groups (48-57 years and 58-67 years) tend to report LBP more frequently than the younger cleaners in the lower age groups $\left(72.5 \% ; \chi^{2}=21.68, P<0.001\right)$. Male cleaners $(83.3 \%)$ also tend to report LBP more frequently than the female counterparts $\left(83.3 \%\right.$ vs. $72.5 \%, \chi^{2}=6.46$, $P<0.011$ ), just as participants with qur'anic and primary education showed higher prevalence rate of approximately $80 \%-85 \%$, compared with their counterparts with secondary and tertiary education with the prevalence rate of $73.4 \%$ and $53.3 \%$, respectively $\left(\chi^{2}=8.00, P<0.046\right)$ [Table 2]. Participants who have worked for 10 years or over had the highest prevalence rate of $94.5 \%$ followed by those that have worked for 7-9 years $(72.2 \%)$, while the least prevalence was found among those with $4-6$ years $(48.3 \%)\left(\chi^{2}=73.34\right.$, $P<0.00)$.

\section{Risk factors of low back pain among cleaners}

Originally, respondents with LBP were asked to consider 13 risk factors and indicate the extent to which each can contribute to the occurrence of their LBP on a Likert scale ranging from 1 (indicating irrelevant) to 4 (indicating major significant). For each risk factor, their responses were dichotomised into 'not important' (responses 1 and 2) and 'important' (responses 3 and 4). Importance responses were then expressed in the percentages for each risk factor. Twelve of the 13 risk factors were chosen by more than $50 \%$ of the respondents as the important contributors to LBP on their job [Table 4]. The risk factors that were most frequently identified by cleaners as important were performing the same task over 
Yunoos and Dankoly: Low back pain among street cleaning workers in Nigeria

\begin{tabular}{|c|c|c|}
\hline Variable/question & Categories & Frequency (\%) \\
\hline \multirow[t]{2}{*}{ Have you ever been hospitalised because of low back pain trouble? } & No & $317(83.2)$ \\
\hline & Yes & $64(16.8)$ \\
\hline \multirow[t]{2}{*}{ Have you ever had to change jobs or duties because of low back trouble? } & No & $90(23.6)$ \\
\hline & Yes & $291(76.4)$ \\
\hline \multirow{5}{*}{$\begin{array}{l}\text { What is the total length of time that you have had low back trouble during the past } \\
12 \text { months? }\end{array}$} & 0 days & $60(15.7)$ \\
\hline & $1-7$ days & $167(43.8)$ \\
\hline & $8-30$ days & $17(4.5)$ \\
\hline & More than 30 days but not everyday & $65(17.1)$ \\
\hline & Everyday & $72(18.9)$ \\
\hline \multicolumn{3}{|l|}{ Has low back trouble caused you to reduce your activity during the last 12 months? } \\
\hline \multirow[t]{2}{*}{ c. Work activity (at home or away from home)? } & No & $65(17.1)$ \\
\hline & Yes & $316(82.9)$ \\
\hline \multirow[t]{2}{*}{ d. Leisure activity? } & No & $85(22.3)$ \\
\hline & Yes & $296(77.7)$ \\
\hline \multirow{4}{*}{$\begin{array}{l}\text { What is the total length of time that low back trouble has prevented you from doing } \\
\text { your normal work (at home or away from home) during the past } 12 \text { months? }\end{array}$} & 0 days & $226(59.3)$ \\
\hline & 1-7 days & $74(19.4)$ \\
\hline & 8-30 days & $41(10.8)$ \\
\hline & $>30$ days & $40(10.5)$ \\
\hline \multirow{2}{*}{$\begin{array}{l}\text { Have you been seen by a doctor, physiotherapist or other such person because of } \\
\text { low back trouble during the last } 12 \text { months? }\end{array}$} & No & $279(73.2)$ \\
\hline & Yes & $102(26.8)$ \\
\hline \multirow[t]{2}{*}{ Have you had low back trouble at any time during the last 7 days? } & No & $171(44.9)$ \\
\hline & Yes & $210(55.1)$ \\
\hline
\end{tabular}

\begin{tabular}{|c|c|c|c|c|}
\hline \multirow[t]{2}{*}{ Variables } & \multicolumn{2}{|c|}{$\begin{array}{l}\text { Prevalence of low } \\
\text { back pain }\end{array}$} & \multirow[t]{2}{*}{$\chi^{2}$} & \multirow[t]{2}{*}{$P$} \\
\hline & No & Yes & & \\
\hline \multicolumn{5}{|l|}{ Age group (years) } \\
\hline $18-27$ & $21(40.9)$ & $31(59.1)$ & 21.68 & 0.001 \\
\hline $28-37$ & $23(27.7)$ & $60(72.3)$ & & \\
\hline $38-47$ & $29(20.6)$ & $112(79.4)$ & & \\
\hline $48-57$ & $8(9.9)$ & $73(90.1)$ & & \\
\hline $58-67$ & $2(8.3)$ & $22(91.7)$ & & \\
\hline \multicolumn{5}{|l|}{ Sex } \\
\hline Male & $34(16.7)$ & $169(83.3)$ & 6.46 & 0.011 \\
\hline Female & $49(27.5)$ & $129(72.5)$ & & \\
\hline \multicolumn{5}{|l|}{ Educational level } \\
\hline Qur'an school & $27(19.6)$ & $111(80.4)$ & 8.00 & 0.046 \\
\hline Primary & $27(18.5)$ & $119(81.5)$ & & \\
\hline Secondary & $22(26.8)$ & $60(73.2)$ & & \\
\hline Tertiary & $7(46.7)$ & $8(53.3)$ & & \\
\hline \multicolumn{5}{|c|}{ Years of working experience } \\
\hline $1-3$ & $31(36.0)$ & $55(64.0)$ & 73.34 & 0.001 \\
\hline $4-6$ & $31(51.7)$ & $29(48.3)$ & & \\
\hline $7-9$ & $10(27.8)$ & $26(72.2)$ & & \\
\hline$\geq 10$ & $11(5.5)$ & $188(94.5)$ & & \\
\hline
\end{tabular}

and over (91.3\%) and working in the same position for long periods $(82.2 \%)$. The risk factors that were least frequently identified as important are 'unanticipated sudden fall' (31.2\%) and continuing to working when injured or hurt (47.0\%).

\section{Discussion}

Janitorial workers are employed in many houses and government agency, and their job involves cleaning of offices and roads, and sometimes, garbage removal to a central location in offices for collection by sanitation workers. They are often involved in cleaning and sweeping using short brooms and also involved in weeding or cutting of trees or branches often using short hoes and cutlasses or axe, respectively. Their work always involve bending down in sweeping and many often do not use face mask, nor wear boots or any protective foot wear while on the job. Street cleaning workers employed in many private organisations are not currently covered by Nigerian National Health Insurance Scheme and do not enjoy leaves or annual vacations throughout their work life on their jobs.

The present study shows a 12-month LBP prevalence rate of $78.2 \%$ among the cleaning workers. This prevalence rate slightly exceeds the rate of $72 \%$ and $63 \%$ reported by, ${ }^{[13,14]}$ respectively, among janitorial workers in tertiary health institutions in Nigeria. It is similar to the rate observed among peasant farmers in a rural community, also in north-eastern Nigeria $^{[19]}$ just as the street cleaning workers in this study and is also comparable to that of peasant farmers in south-eastern Nigeria. ${ }^{[12]}$ However, this rate is slightly higher than the prevalence rate among peasant farmers at $67 \%$ and $72 \%$ rates in south-western Nigeria. ${ }^{[11]}$ LBP prevalence among the street cleaners also exceeds that of other occupational groups, at the rate of $59.3 \%$ among commercial drivers in Lagos, ${ }^{[20]} 69.8 \%$ among physiotherapists across Nigeria, ${ }^{[21]}$ and at the rate of $58.5 \%$ among bus drivers in central India. ${ }^{[22]}$ The rate also far 
Yunoos and Dankoly: Low back pain among street cleaning workers in Nigeria

\begin{tabular}{|c|c|c|}
\hline \multirow[t]{2}{*}{ Risk factors } & \multicolumn{2}{|c|}{ Frequency (\%) } \\
\hline & Not important & Important \\
\hline Performing the same task over and over & $26(8.7)$ & $272(91.3)$ \\
\hline Carrying heavy loads & $89(29.9)$ & $209(70.1)$ \\
\hline Not enough rest break during the day & $127(42.6)$ & $171(57.4)$ \\
\hline Working in awkward/cramped positions & $65(21.8)$ & $233(78.2)$ \\
\hline Working in the same position for long periods & $53(17.8)$ & $245(82.2)$ \\
\hline Bending or twisting your back in an awkward way & $59(19.8)$ & $239(80.2)$ \\
\hline Reaching or working away from your body & $97(32.6)$ & $201(67.4)$ \\
\hline Unanticipated sudden falls & $205(68.8)$ & $93(31.2)$ \\
\hline Moving heavy materials or equipment & $100(33.6)$ & $198(66.4)$ \\
\hline Working at or near your physical limits & $94(31.5)$ & $204(68.5)$ \\
\hline Continuing to working when injured or hurt & $158(53)$ & $140(47)$ \\
\hline Work scheduling (over time or length of workday) & $85(28.5)$ & $213(71.5)$ \\
\hline Inadequate training in injury prevention & $101(33.9)$ & $197(66.1)$ \\
\hline
\end{tabular}

Totals add up to only 298 (not 381) because some participants did not respond to this subscale of the questionnaire

exceeded those of sanitation workers (45.5\%) who clean the streets in Brazil. ${ }^{[15]}$

That LBP prevalence tend to occur more frequently among those in the older age groups 58-67 years than in lower age groups is consistent with a report from ${ }^{[23]}$ that found the prevalence of LBP to be more for those in the age group between 50 and 60 years for automobile workers in the USA. It is also consistent with the finding by Katz ${ }^{[4]}$ which shows that LBP tend to be more prevalent among those in the older age groups. With the findings in this study that affirm apparent increase in LBP among those in the older age groups, arguments can be made that aging may be an independent factor in the prevalence rate. Furthermore, an identifiable trend that show a high prevalence of $64 \%$ in the service years 1-3 which reduced in the subsequent years (4-6) to $46.3 \%$, and then takes an upward turn to $72.2 \%$ from year $7-9$ on to over $94 \%$ at 10 or more years in service, the hypothesis that LBP incidence increases with age in the general population as reported in a previous study ${ }^{[4]}$ is therefore affirmed.

With the identifiable trend that shows increasing prevalence of LBP with service years as indicated above, argument can also be made for possible coping skills development after the first few years, which wanes in effectiveness in the subsequent years in service. Coping mechanism indicative of ability to return to equilibrium state upon perturbation which decreases with aging (reference on homeostatic equilibrium) may not remain as potent as a worker ages and may be responsible for the upward trend as the street cleaning workers age and accrue years in service. This further affirms aging as an independent factor in the LBP experience among workers regardless of their occupation. That LBP is more prevalent among males than females as observed in the present study is also consistent with findings from ${ }^{[23]}$ which showed a higher prevalence of LBP among male physiotherapists. It is also consistent with findings that shows female tend to have LBP more than their male in the general population. ${ }^{[24]}$
Several explanations may be adduced for the differences in the prevalence by gender. One explanation is that it is possible that jobs are assigned based on capabilities which make men to tend to be assigned to more physically demanding parts of the job such as lifting and tree cutting, more than sweeping duties to which women tend to be more frequently assigned. Another explanation is the societal specific role assignment by gender. In the typical African society such as the one in which the study is conducted, females are naturally expected to be assigned or even request where possible, less physically demanding tasks while men will be assigned the more demanding aspects of the job such as the cutting and the heavy lifting tasks on the job. Higher prevalence among those with lower education is also consistent with report in a study by Tinubu et al. ${ }^{[25]}$ among Nigerian nurses and can be attributed to upward mobility and the tendency for a change in job duty and cadre with education as those with education may be assigned supervisory role. It is also consistent with the report that shows those with low educational attainment tend to be report LBP more than their counterparts with higher education in the American population. ${ }^{[4]}$

A priori comparison that shows similar level of LBP prevalence among the street cleaners in the present study as the prevalence among Nigerian peasant farmers is noteworthy. More so considering that the later occupation is still practiced mainly at an unmechanised mode and small holding scale using manual tools as is still the farming practice in both the forest region in the Southern Nigeria, ${ }^{[12]}$ and in the Sahel region in Northern Nigeria. ${ }^{[19]}$ The prevalence rate that far exceed the rate reported for workers even in other blue collar occupation is an indication that street cleaning as practiced in this North-eastern city in Nigeria, is a high risk occupation for developing LBP and the risk may exceed those of other blue collar industry. On a positive note though, it appears the workers were able to identify the body movement, postures, and specific tasks and work schedule that could pre-dispose them to developing LBP, based on the responses on the risk factors. 
At a high prevalence rate of $78.2 \%$ and a crude point (7 days) prevalent rate of $55.1 \%$, street cleaning can be considered to be a job with a high risk for LBP. It is a job with risk that is comparable to the risk for farming occupation and second only to farming in point prevalence. ${ }^{[19]}$ Whether the workers were familiar with the strategies to mediate or minimize the progression of this pain is however unknown. With only $26.8 \%$ of the total respondents ( $42.1 \%$ of those who has LBP) seen by a physiotherapist or doctor as a result of their back trouble in the past 12 months, there are indications that some of the workers demonstrated a health-seeking behavior that can be considered to be satisfactory. That LBP constitutes a threat to the workers' health and quality of life is further demonstrated by the response that show it may have caused some of the workers to be hospitalized, and many to be reassigned to another duties/LBP is a daily experience for many of these workers, caused some to reduce their work activity and affect performance of work activity at home.

It can be argued that there is hardly any blue-collar occupation that does not attract work-related musculoskeletal disorder as a risk. Given that work-related musculoskeletal disorders may not be considered a disease with consequences of mortality per se, there is a risk of not paying the necessary attention to LBP as a job hazards in general, especially in low health resources countries such as Nigeria. The challenges posed by LBP for the workers and its impact may not be duly publicized and may not attract attention to the scale of the occupational diseases' attendants in jobs such as coal mining or working in asbestos factory. For this occupational group, however, the risk attendant on the job can be minimized through ergonomic education and employers' sensitization to workplace job safety and concern for employees' health and working condition.

\section{Limitations}

Participants were dichotomized into groups, although no substantial differences in the results are expected if the data were not dichotomized, different inferential statistical analysis could have been warranted and may lead to an insubstantially different result interpretation. Furthermore, the calculated sample size for this study was 420 , but 381 participants were surveyed making type II error a possible threat, and therefore warranting caution in the interpretation of the findings. The sample size is however within the range for similar studies in other occupational groups such as farmers and janitorial workers with which comparison of the result of this study were made. Nevertheless, overall, the findings in this study affirm LBP as a job hazard among blue collar workers. For this group of blue-collar workers, this study makes contributions that have implications on the occupational health of environmental sanitation industrial sector of the national economy.

\section{Conclusions}

This study shows a high 12-month prevalence rate of 78.2\% among street cleaners in Maiduguri. It also revealed that LBP tend to occur more frequently among cleaners in older age groups than those in the younger age group, among male cleaners more frequently than their female counterparts, among those with elementary or qur'anic education than among those with secondary or higher education and among those who have been on the job for more years than those with less years on the job. Performing the same task over and over and working in the same position for long periods were important pre-disposing factors most frequently identified by the workers. The study suggests the need for workers education, and use of ergonomically fit tools and equipment as potential solution to mitigating the high prevalence of LBP among this cohort of workers.

\section{Acknowledgement}

We acknowledge the support of Borno State Environmental Protection Agency.

\section{Financial support and sponsorship}

Nil.

\section{Conflicts of interest}

There are no conflicts of interest.

\section{References}

1. Kovacs FM, Abraira V, Pena A. Effect of firmness of mattress on chronic non-specific low-back pain: Randomised, double-blind, controlled, multicentre trial. Lancet 2003;326:1599-604.

2. Solecki L. Low back pain among farmers exposed to whole body vibration: A literature review. Med Pr 2011;62:187-202.

3. Niyyi A. Physiotherapy in the Management of Low Back Pain. $1^{\text {st }}$ ed. Lagos, Nigeria: Adtools Communication Ltd.; 1991. p. 1-3.

4. Katz JN. Lumbar disc disorders and low-back pain: Socioeconomic factors and consequences. J Bone Joint Surg Am 2006;2:21-4.

5. Kuiper JI. Assessing the work-relatedness of nonspecific low-back pain. Scand J Work Environ Health 2005;31:237-43.

6. Manchikanti L. Epidemiology of low back pain. Pain Physician 2000;3:167-92.

7. Frank A. Low back pain. BMJ 1993;306:901-9.

8. World Health Organization. Burden of Musculoskeletal Conditions of the Start of the New Millennium: Report of WHO Scientific Group. Geneva: World Health Organization; 2013.

9. Mbamali EL, Badoe EA, Archampong EQ, Da Rocha Affodu JI. Principles and Practice of Surgery Including Pathology in the Tropics. $3^{\text {rd }}$ ed. Ghana: Ghana Publishing Corporation; 2000. p. 1052.

10. Omokhodion FO, Umar US, Ogunnowo BE. Prevalence of low back pain among staff in a rural hospital in Nigeria. Occup Med (Lond) 2000;50:107-10

11. Fabunmi AA, Aba SO, Odunaiya NA. Prevalence of low back pain among peasant farmers in a rural community in South West Nigeria. Afr J Med Med Sci 2005;34:259-62.

12. Birabi BN, Dienye PO, Ndukwu GU. Prevalence of low back pain among peasant farmers in a rural community in South South Nigeria. Rural Remote Health 2012;12:1920.

13. Adebusoye LA, Ogunbode AM, Alonge TO. Factors associated with low back pain among cleaners in a tertiary hospital in Nigeria. Res J Health Sci 2015;3:100-12.

14. Ilesanmi OS, Omotoso B, Falana D. Health problems and health seeking behaviour of hospital cleaners in a tertiary health facility in South west Nigeria. Acad J Interdiscip Stud 2014;3:187-91.

15. Pataro AM, de Cássia R, Fernandes P. Heavy physical work and low back pain: The reality in urban cleaning. Rev Bras Epidemiol 2014;17:1-15.

16. Barrero LH, Hsu YH, Terwedow H, Perry MJ, Dennerlein JT, Brain JD. Prevalence and physical determinants of low back pain in a rural Chinese population. Spine (Phila Pa 1976) 2006;31:2728-34.

17. Kuorinka I, Jonsson B, Kilbom A, Vinterberg H, Biering-Sorensen F, 
Andersson G, et al. Standardised Nordic questionnaires for the analysis of musculoskeletal symptoms. Appl Ergon 1987;18:233-7.

18. Ohlsson K, Attewell RG, Johnsson B. An assessment of neck and upper extremity disorders by questionnaire and clinical examination. Ergonomics 1994;37:891-7.

19. Umar SA, Istifanus UW, Oyeyemi AY, Rufai AA, Oyeyemi AL, Maduagwu SM. Prevalence of low back pain among peasant farmers in a rural community, North Eastern Nigeria. Asian Acad Res J Multidiscip 2014;1:64-79.

20. Akinbo SR, Odebiyi DO, Giwa SO. Prevalence of work related low back pain. Niger J Med Rehabil 2008;9:1-2.

21. Adegoke B, Akobu A, Oyeyemi AL. Work-related musculoskeletal disorders among Nigerian physiotherapists. BMC Musculoskelet Disord 2008;9:112.

22. Amod K, Mohan D, Varghese M. Effect of whole body vibration on low back pain. Spine (Phila Pa 1976) 2012;24:2506-15.

23. Glover W, McGregor A, Sullivan C, Hague J. Work-related musculoskeletal disorders affecting cleaners. J Physiol 2010;91:138-47.

24. Cromie P, West DJ, Claire S. Work-related musculoskeletal disorder affecting members of the chartered society of physiotherapy. J Physiol 2000;6:47-53

25. Tinubu BM, Mbada CE, Oyeyemi AL, Fabunmi AA. Work-related musculoskeletal disorders among Nurses in Ibadan, South-West Nigeria: A cross-sectional survey. BMC Musculoskelet Disord 2010;11:12. 